\title{
KARAKTERISTIK, MOTIVASI DAN AKTIVITAS WISATAWAN ASIA DI KELURAHAN UBUD
}

\author{
Axel Christine Pratama \\ I G.P.B Sasrawan Mananda \\ I Nyoman Sudiarta \\ Email : axelchristine@gmail.com \\ PS. S1 Industri Perjalanan Wisata \\ Fakultas Pariwisata UNUD
}

\begin{abstract}
The types of the data that are used in this research are primary and secondary data. All the datas are collected through an observation method, questionnaires, literature study and documentation. The sample is collected by non-random sampling method. Analysis technique that is used in this research is qualitative descriptive analysis. This research result showed that the Asia tourists who came to Ubud for the first time are 96 tourists and the repeater tourists are 9 (nine) people. The characteristic of the tourists according to the age who came to Ubud the most is tourists between 26-36 years old and most of the gender are male. Most of the tourists are from China. According to the occupation, most of the tourists are student with bachelor degree, they got the information about Ubud from their friends and they came to Ubud with groups. Most of them are the first timer visitors and they came by car or bus and came to Bali by airplane. Mode of transportation which is used when the tourists are in Ubud mostly is rented vehicles and stay in Ubud for a day without the tour. The attraction they want to see in Ubud is the culture with the expenses around Rp 201.000-300.000 in a day. According to the tourists who came to Ubud, Ubud's environment is very clean and safe, so they feel very satisfied and they definitely will come back again to Ubud. The motivation of the tourists who came to Ubud the most is the tourists with the pleasure motivation and the main activity they want to do is to visit Ubud market.
\end{abstract}

\section{Key words: Characteristic, Motivation, Activity, Asian Tourists}

\section{Latar Belakang}

Perubahan pola konsumsi wisatawan berubah selera sesuai dengan keinginan dan kebutuhannya, misalnya untuk menikmati kreasi budaya, Ubud merupakan salah satu daerah wisata di Bali yang mengunggulkan seni dan budaya, sehingga wisatawan yang datang ke Bali yang tertarik akan budaya akan berkunjung ke Ubud. Ubud tentu saja menyediakan aktivitas-aktivitas kepariwisatan yang dapat dilakukan oleh wisatawan ketika mereka berkunjung ke Ubud. Para wisatawan asia yang mengunjungi Ubud tentu saja memiliki motivasi yang berbeda-beda ketika mengunjungi Ubud. Berdasarkan hal tersebut, maka dapat diketahui bahwa perjalanan yang dilakukan wisatawan tidak selalu sama, aktivitas yang dilakukan di destinasi wisata tersebut juga berbeda-beda karena dipengaruhi oleh motivasi wisatawan serta kondisi tertentu. Sekarang ini dapat dilihat bahwa kunjungan wisatawan mancanegara ke Bali yang paling banyak adalah wisatawan Asia terutama wisatawan yang berasal dari China. Oleh sebab itu, peneliti ingin melakukan penelitian tentang karakteristik, motivasi dan aktivitas wisatawan Asia yang datang berkunjung ke Ubud.

\section{Metodologi Penelitian}

Lokasi penelitian dilakukan di Kelurahan Ubud, Kabupaten Gianyar, Bali. Jenis data yang digunakan dalam penelitian ini adalah data kualitatif dan data kuantitatif. Sumber data dalam penelitian ini adalah data primer dan data sekunder. Teknik pengumpulan data dalam penelitian ini adalah observasi, kuesioner, studi kepustakaan dan dokumentasi. Teknik pengambilan sampel yang digunakan dalam penelitian ini adalah teknik pengambilan sampel non-random secara kebetulan. Untuk menentukan sampel dalam 
penelitian ini digunakan teknik pengambilan sampel yang mana banyaknya responden yang diambil untuk mengisi kuesioner bisa 5 (lima) atau 10 (sepuluh) kali. Teknik analisis data data yang dipergunakan dalam penelitian ini yaitu teknik analisis data deskriptif kualitatif.

III. Hasil

\section{Karakteristik Wisatawan Asia Berdasarkan Umur}

Karakteristik wisatawan Asia berdasarkan umur yang datang mengunjungi Ubud yang paling banyak adalah wisatawan Asia yang berusia 26-36 tahun yaitu sebanyak 55 orang dan yang paling sedikit adalah wisatawan yang berusia antara 15-25 tahun.

2. Karakteristik Wisatawan Asia Berdasarkan Jenis Kelamin

Karakteristik wisatawan Asia berdasarkan jenis kelamin yang paling banyak adalah wisatawan yang berjenis kelamin laki-laki yaitu sebanyak 54 orang atau sejumlah $51.43 \%$.

\section{Karakteristik Wisatawan Asia} Berdasarkan Negara Asalnya Tabel 3.1

\begin{tabular}{|c|c|c|c|c|}
\hline \multirow{2}{*}{ No } & \multirow[b]{2}{*}{$\begin{array}{c}\text { Negara } \\
\text { Asal }\end{array}$} & \multicolumn{2}{|c|}{$\begin{array}{c}\text { Jumlah } \\
\text { Wisatawan }\end{array}$} & \multirow[b]{2}{*}{$\begin{array}{c}\text { Persentas } \\
\text { e (\%) }\end{array}$} \\
\hline & & $\begin{array}{c}\text { First } \\
\text { Time } \\
r\end{array}$ & $\begin{array}{c}\text { Repeate } \\
r\end{array}$ & \\
\hline 1. & China & 60 & 1 & 58.10 \\
\hline 2. & Taiwan & 13 & 1 & 13.33 \\
\hline 3. & $\begin{array}{l}\text { Singapor } \\
\mathrm{e}\end{array}$ & 4 & 2 & 5.71 \\
\hline 4. & Malaysia & 8 & 2 & 9.52 \\
\hline 5. & Korea & 3 & - & 2.86 \\
\hline 6. & India & 3 & - & 2.86 \\
\hline 7. & Thailand & 5 & 1 & 5.71 \\
\hline 8. & Jepang & - & 2 & 1.91 \\
\hline \multirow{2}{*}{\multicolumn{2}{|c|}{ Jumlah }} & 96 & 9 & \multirow{2}{*}{100} \\
\hline & & \multicolumn{2}{|c|}{105} & \\
\hline
\end{tabular}

Sumber: Data hasil penelitian, 2016

Berdasarkan Tabel 3.1 dapat dilihat bahwa kunjungan wisatawan Asia yang paling banyak adalah wisatawan yang berasal dari China dan yang paling sedikit adalah wisatawan yang berasal dari Jepang.

4. Karakteristik Wisatawan Asia Berdasarkan Jenis Pekerjaan

Tabel 4.1

\begin{tabular}{|c|c|c|c|c|}
\hline \multirow{2}{*}{ No } & \multirow{2}{*}{$\begin{array}{c}\text { Jenis } \\
\text { Pekerjaa }\end{array}$} & \multicolumn{2}{|c|}{$\begin{array}{c}\text { Jumlah } \\
\text { Wisatawan }\end{array}$} & \multirow{2}{*}{$\begin{array}{c}\text { Persenta } \\
\text { se (\%) }\end{array}$} \\
\cline { 3 - 4 } & $\mathbf{n}$ & $\begin{array}{c}\text { First } \\
\text { Time }\end{array}$ & $\begin{array}{c}\text { Repeat } \\
\text { er }\end{array}$ & \\
\hline
\end{tabular}

\begin{tabular}{|c|c|c|c|c|}
\hline & & $r$ & & \\
\hline 1. & Pelajar & 23 & 2 & 23.81 \\
\hline 2. & Karyawan & 15 & 2 & 16.19 \\
\hline 3. & Pengusaha & 13 & 2 & 14.29 \\
\hline 4. & Insinyur & 15 & - & 14.29 \\
\hline 5. & Sales & 6 & - & 5.71 \\
\hline 6. & Dokter & 5 & 1 & 5.71 \\
\hline 7. & $\begin{array}{l}\text { Hair } \\
\text { Stylish }\end{array}$ & 3 & - & 2.86 \\
\hline 8. & $\begin{array}{l}\text { Guru/Dos } \\
\text { en }\end{array}$ & 5 & 1 & 5.71 \\
\hline 9. & Chef & 2 & - & 1.91 \\
\hline 10. & Manager & 3 & - & 2.86 \\
\hline 11. & DJ & 1 & - & 0.95 \\
\hline 12. & Perawat & 1 & - & 0.95 \\
\hline 13. & HRD & 1 & - & 0.95 \\
\hline 14. & Professor & 1 & - & 0.95 \\
\hline 15. & Peneliti & 1 & - & 0.95 \\
\hline 16. & Fotografer & 1 & 1 & 0.95 \\
\hline 17. & Pensiun & 1 & & 0.95 \\
\hline \multirow{2}{*}{\multicolumn{2}{|c|}{ Jumlah }} & 96 & 9 & \multirow{2}{*}{100} \\
\hline & & \multicolumn{2}{|c|}{105} & \\
\hline
\end{tabular}

Sumber: Data hasil penelitian, 2016

Berdasarkan Tabel 4.1 dapat dilihat bahwa wisatawan Asia yang datang berkunjung ke Ubud yang paling banyak adalah wisatawan yang pekerjaannya adalah pelajar yaitu sebanyak 25 orang atau sejumlah $23.81 \%$.

\section{Karakteristik Wisatawan Asia}

\section{Berdasarkan Tingkat Pendidikan}

Karakteristik wisatawan Asia berdasarkan tingkat pendidikannya yang paling banyak adalah wisatawan dengan jenjang pendidikan sarjana yaitu sebanyak 69 orang atau sejumlah $65.71 \%$ dan yang paling sedikit adalah wisatawan dengan jenjang pendidikan diploma.

6. Karakteristik Wisatawan Asia Berdasarkan Sumber Informasi Tabel 6.1

\begin{tabular}{|c|l|c|c|c|}
\hline \multirow{2}{*}{$\begin{array}{c}\text { No } \\
\cdot\end{array}$} & \multirow{2}{*}{$\begin{array}{c}\text { Sumber } \\
\text { Informas } \\
\mathbf{i}\end{array}$} & \multicolumn{2}{|c|}{$\begin{array}{c}\text { Jumlah } \\
\text { Wisatawan }\end{array}$} & \multirow{2}{*}{ Persentas } \\
\cline { 3 - 4 } & $\begin{array}{c}\text { First } \\
\text { Time } \\
\boldsymbol{r}\end{array}$ & $\begin{array}{c}\text { Repeat } \\
\text { er }\end{array}$ & \\
\hline 1. & Teman & 32 & 2 & 32.38 \\
\hline 2. & TV/Radio & 1 & - & 0.95 \\
\hline 3. & Brosur & 2 & - & 1.91 \\
\hline 4. & $\begin{array}{l}\text { Travel } \\
\text { Agent }\end{array}$ & 49 & 5 & 51.42 \\
\hline 5. & $\begin{array}{l}\text { Internet } \\
\text { (Lainnya) }\end{array}$ & 10 & 2 & 11.43 \\
\hline 6. & Keluarga & 2 & - & 1.91 \\
\hline
\end{tabular}




\begin{tabular}{|c|c|c|c|}
\hline (Lainnya) & & & \\
\hline \multirow{2}{*}{ Jumlah } & 96 & 9 & \multirow{2}{*}{100} \\
\cline { 2 - 3 } & \multicolumn{2}{|c|}{105} & \\
\hline
\end{tabular}

Sumber: Data hasil penelitian, 2016

Berdasarkan Tabel 6.1 dapat dilihat bahwa kunjungan wisatawan Asia ke Ubud yang paling banyak adalah wisatawan yang mendapatkan informasi dari travel agent dan yang paling sedikit adalah wisatawan yang mendapatkan informasinya dari $\mathrm{TV}$ atau radio.

7. Karakteristik Wisatawan Asia Berdasarkan Cara Berkunjung

Karakteristik wisatawan Asia berdasarkan cara berkunjung ke Ubud yang paling banyak adalah wisatawan yang berkunjung ke Ubud bersama group yaitu sebanyak 53 orang dan yang paling sedikit adalah wisatawan yang berkunjung ke Ubud sendiri.

\section{Karakteristik Wisatawan Asia}

Berdasarkan Frekuensi Berkunjung

Karakteristik wisatawan Asia berdasarkan frekuensi berkunjung yang paling banyak adalah wisatawan yang baru datang mengunjungi Ubud untuk pertama kali yaitu sebanyak 96 orang wisatawan dan wisatawan yang berkunjung ke Ubud lebih dari 1 (satu) kali ada sebanyak 9 (sembilan) orang wisatawan.

9. Karakteristik Wisatawan Asia Berdasarkan Jenis Transportasi Tabel 9.1

\begin{tabular}{|c|c|c|c|c|}
\hline \multirow{2}{*}{ No } & \multirow{2}{*}{$\begin{array}{c}\text { Jenis } \\
\text { Transport } \\
\text { asi }\end{array}$} & \multicolumn{2}{|c|}{$\begin{array}{c}\text { Jumlah } \\
\text { Wisatawan }\end{array}$} & \multirow[b]{2}{*}{$\begin{array}{c}\text { Persenta } \\
\text { se }(\%)\end{array}$} \\
\hline & & $\begin{array}{c}\text { First } \\
\text { Tim } \\
\text { er }\end{array}$ & $\begin{array}{l}\text { Repeat } \\
\quad \text { er }\end{array}$ & \\
\hline 1. & Mobil/Bus & 94 & 8 & 97.14 \\
\hline 2. & $\begin{array}{l}\text { Sepeda } \\
\text { Motor }\end{array}$ & 2 & 1 & 2.86 \\
\hline 3. & Sepeda & - & - & - \\
\hline 4. & Jalan Kaki & - & - & - \\
\hline \multirow{2}{*}{\multicolumn{2}{|c|}{ Jumlah }} & 96 & 9 & \multirow{2}{*}{100} \\
\hline & & \multicolumn{2}{|c|}{105} & \\
\hline
\end{tabular}

Sumber: Data hasil penelitian, 2016

Berdasarkan Tabel 9.1 dapat dilihat bahwa karakteristik wisatawan Asia berdasarkan jenis transportasi yang digunakan untuk berkunjung ke Ubud adalah wisatawan yang menggunakan mobil atau bus.

\section{Karakteristik Wisatawan Asia}

\section{Berdasarkan Jalur Transportasi}

Karakteristik wisatawan Asia berdasarkan jalur transportasi yang digunakan untuk datang ke Bali adalah seluruh wisatawan yaitu sejumlah 105 orang wisatawan atau sejumlah 100\% menggunakan jalur transportasi udara.

11. Karakteristik Wisatawan Asia
Berdasarkan Moda Transportasi Tabel 11.1

\begin{tabular}{|c|c|c|c|c|}
\hline \multirow[b]{2}{*}{$\begin{array}{l}\mathbf{N} \\
\text { o. }\end{array}$} & \multirow{2}{*}{$\begin{array}{c}\text { Moda } \\
\text { Transport } \\
\text { asi }\end{array}$} & \multicolumn{2}{|c|}{$\begin{array}{c}\text { Jumlah } \\
\text { Wisatawan }\end{array}$} & \multirow{2}{*}{$\begin{array}{c}\text { Persenta } \\
\text { se (\%) }\end{array}$} \\
\hline & & $\begin{array}{c}\text { First } \\
\text { Tim } \\
\text { er }\end{array}$ & $\begin{array}{c}\text { Rerpeat } \\
\text { er }\end{array}$ & \\
\hline 1. & $\begin{array}{l}\text { Kendaraan } \\
\text { Pribadi }\end{array}$ & 1 & - & 0.95 \\
\hline 2. & $\begin{array}{l}\text { Kendaraan } \\
\text { Sewa }\end{array}$ & 89 & 8 & 92.38 \\
\hline 3. & $\begin{array}{l}\text { Kendaraan } \\
\text { Umum } \\
\end{array}$ & 4 & - & 3.81 \\
\hline 4. & \begin{tabular}{|l|} 
Sepeda \\
Motor \\
\end{tabular} & 2 & 1 & 2.86 \\
\hline \multirow{2}{*}{\multicolumn{2}{|c|}{ Jumlah }} & 96 & 9 & \multirow[t]{2}{*}{100} \\
\hline & & \multicolumn{2}{|c|}{105} & \\
\hline
\end{tabular}

Sumber: Data hasil penelitian, 2016

Berdasarkan Tabel 11.1 dapat dilihat bahwa karakteristik wisatawan Asia berdasarkan moda transportasi yang digunakan selama berada di Ubud yang paling banyak adalah wisatawan yang menggunakan kendaraan sewa dan yang paling sedikit adalah wisatawan yang menggunakan kendaraan pribadi.

12. Karakteristik Wisatawan Asia Berdasarkan Lama Tinggal di Ubud Tabel 12.1

\begin{tabular}{|c|c|c|c|c|}
\hline \multirow{2}{*}{ No } & \multirow{2}{*}{$\begin{array}{c}\text { Lama } \\
\text { Tingga } \\
\quad \text { I }\end{array}$} & \multicolumn{2}{|c|}{$\begin{array}{c}\text { Jumlah } \\
\text { Wisatawan }\end{array}$} & \multirow{2}{*}{$\begin{array}{c}\text { Persentas } \\
\text { e }(\%)\end{array}$} \\
\hline & & $\begin{array}{c}\text { First } \\
\text { Time } \\
r\end{array}$ & $\begin{array}{c}\text { Repeate } \\
r\end{array}$ & \\
\hline 1. & $<6$ jam & 34 & 3 & 35.24 \\
\hline 2. & $>6$ jam & 11 & 1 & 11.43 \\
\hline 3. & 1 hari & 41 & 3 & 41.91 \\
\hline 4. & $\begin{array}{l}2 \text { hari } \\
\text { (lebih } \\
\text { dari } 1 \\
\text { hari) }\end{array}$ & 4 & 1 & 4.76 \\
\hline 5. & $\begin{array}{l}3 \text { hari } \\
\text { (lebih } \\
\text { dari } 1 \\
\text { hari) }\end{array}$ & 5 & 1 & 5.71 \\
\hline 6. & $\begin{array}{l}5 \text { hari } \\
\text { (lebih } \\
\text { dari } 1 \\
\text { hari) }\end{array}$ & 1 & - & 0.95 \\
\hline \multicolumn{2}{|c|}{ Jumlah } & 96 & $\begin{array}{ll} & 9 \\
05 & \end{array}$ & 100 \\
\hline
\end{tabular}

Sumber: Data hasil penelitian, 2016 
Berdasarkan Tabel 12.1 dapat dilihat karakteristik wisatawan Asia berdasarkan lama tinggal di Ubud yang paling banyak adalah wisatawan yang menetap di Ubud selama 1 (satu) hari.

\section{Karakteristik Wisatawan Asia} Berdasarkan Tipologi Perjalanan

Karakteristik Wisatawan Asia berdasarkan tipologi perjalanannya selama berkunjung ke Ubud yang paling banyak adalah wisatawan yang datang berkunjung ke Ubud dengan tidak menggunakan tour yaitu sebanyak 55 orang atau sejumlah dan yang menggunakan tour adalah sebanyak 50 orang.

14. Karakteristik Wisatawan Asia Berdasarkan Jenis Daya Tarik yang Ingin Dikunjungi

Karakteristik wisatawan Asia berdasarkan jenis daya tarik yang ingin dikunjungi selama mereka berada di Ubud yang paling banyak adalah wisatawan yang ingin mengunjungi daya tarik wisata kebudayaan yaitu sebanyak 75 orang wisatawan atau sejumkah $71.43 \%$ dan wisatawan yang ingin mengunjungi wisata alam yaitu sebanyak 30 orang wisatawan atau sejumlah $28.57 \%$.

15. Karakteristik Wisatawan Asia Berdasarkan Pengeluaran RataRata per Hari

Tabel 15.1

\begin{tabular}{|c|c|c|c|c|}
\hline \multirow[t]{2}{*}{ No } & \multirow{2}{*}{$\begin{array}{c}\text { Pengeluar } \\
\text { an Rata- } \\
\text { Rata per } \\
\text { Hari }\end{array}$} & \multicolumn{2}{|c|}{$\begin{array}{c}\text { Jumlah } \\
\text { Wisatawan }\end{array}$} & \multirow[t]{2}{*}{$\begin{array}{c}\text { Persenta } \\
\text { se }(\%)\end{array}$} \\
\hline & & $\begin{array}{c}\text { First } \\
\text { Time } \\
r\end{array}$ & $\begin{array}{l}\text { Repeat } \\
\quad \text { er }\end{array}$ & \\
\hline 1. & $<100.000$ & - & - & - \\
\hline 2. & $\begin{array}{l}100.000- \\
200.000\end{array}$ & 14 & 3 & 16.19 \\
\hline 3. & $\begin{array}{l}201.000- \\
300.000\end{array}$ & 37 & 3 & 38.10 \\
\hline 4. & $\begin{array}{l}301.000- \\
400.000 \\
\end{array}$ & 29 & 2 & 29.52 \\
\hline 5. & $\begin{array}{l}401.000- \\
500.000\end{array}$ & 15 & 1 & 15.24 \\
\hline 6. & $>500.000$ & 1 & - & 0.95 \\
\hline \multirow{2}{*}{\multicolumn{2}{|c|}{ Jumlah }} & 96 & 9 & \multirow{2}{*}{100} \\
\hline & & \multicolumn{2}{|c|}{105} & \\
\hline
\end{tabular}

Sumber: Data hasil penelitian, 2016

Berdasarkan Tabel 15.1 dapat dilihat bahwa karakteristik wisatawan Asia berdasarkan pengeluaran rata-rata per hari yang paling banyak adalah wisatawan yang mengeluarkan uang rata-rata Rp. 201.000-300.000 per hari.

\section{Karakteristik Wisatawan Asia Berdasarkan Kesan Terhadap Kebersihan}

\begin{tabular}{|c|c|c|c|c|}
\hline \multirow{3}{*}{ No } & \multirow{3}{*}{$\begin{array}{c}\text { Kesan } \\
\text { Tentang } \\
\text { Kebersih } \\
\text { an }\end{array}$} & \multicolumn{2}{|c|}{ Tabel 16.1} & \multirow{3}{*}{$\begin{array}{c}\text { Persenta } \\
\text { se }(\%)\end{array}$} \\
\hline & & \multicolumn{2}{|c|}{$\begin{array}{c}\text { Jumlah } \\
\text { Wisatawan }\end{array}$} & \\
\hline & & $\begin{array}{c}\text { First } \\
\text { Time } \\
r\end{array}$ & $\begin{array}{c}\text { Repeat } \\
\text { er }\end{array}$ & \\
\hline 1. & $\begin{array}{l}\text { Sangat } \\
\text { Bersih }\end{array}$ & 45 & 4 & 46.67 \\
\hline 2. & Bersih & 38 & 4 & 40 \\
\hline 3. & $\begin{array}{l}\text { Cukup } \\
\text { Bersih }\end{array}$ & 13 & 1 & 13.33 \\
\hline 4. & $\begin{array}{l}\text { Tidak } \\
\text { Bersih }\end{array}$ & - & - & - \\
\hline 5. & $\begin{array}{l}\text { Sangat } \\
\text { Tidak } \\
\text { Bersih }\end{array}$ & - & - & - \\
\hline \multirow{2}{*}{\multicolumn{2}{|c|}{ Jumlah }} & 96 & 9 & \multirow[t]{2}{*}{100} \\
\hline & & & 05 & \\
\hline
\end{tabular}

Sumber: Data hasil penelitian, 2016

Berdasarkan Tabel 16.1 dapat dilihat bahwa karakteristik wisatawan Asia berdasarkan kesan terhadap kebersihan yang paling banyak adalah wisatawan yang menganggap Ubud sangat dan yang paling sedikit adalah wisatawan yang menganggap lingkungan Ubud cukup bersih.

17. Karakteristik Wisatawan Asia Berdasarkan Kesan Terhadap Kondisi Keamanan

Tabel 17.1

\begin{tabular}{|c|c|c|c|c|}
\hline \multirow{2}{*}{$\begin{array}{c}\text { No } \\
\text {. }\end{array}$} & \multirow{2}{*}{$\begin{array}{c}\text { Kesan } \\
\text { Tentang } \\
\text { Kondisi } \\
\text { Kemana } \\
\text { n }\end{array}$} & \multicolumn{2}{|c|}{$\begin{array}{c}\text { Jumlah } \\
\text { Wisatawan }\end{array}$} & \multirow{2}{*}{$\begin{array}{c}\text { Persentas } \\
\text { e (\%) }\end{array}$} \\
\hline & & $\begin{array}{c}\text { First } \\
\text { Time } \\
r\end{array}$ & $\begin{array}{c}\text { Repeate } \\
r\end{array}$ & \\
\hline 1. & $\begin{array}{l}\text { Sangat } \\
\text { Aman }\end{array}$ & 32 & 3 & 33.34 \\
\hline 2. & Aman & 52 & 5 & 54.28 \\
\hline 3. & $\begin{array}{l}\text { Cukup } \\
\text { Aman }\end{array}$ & 12 & 1 & 12.38 \\
\hline 4. & $\begin{array}{l}\text { Kurang } \\
\text { Aman }\end{array}$ & - & - & - \\
\hline 5. & $\begin{array}{l}\text { Sangat } \\
\text { Kurang } \\
\text { Aman }\end{array}$ & - & - & - \\
\hline \multicolumn{2}{|c|}{ Jumlah } & 96 & 9 & 100 \\
\hline
\end{tabular}

Sumber: Data hasil penelitian, 2016

Berdasarkan Tabel 17.1 dapat dilihat bahwa karakteristik wisatawan Asia berdasarkan kesan terhadap kondisi keamanan yang ada di 
Ubud yang paling banyak adalah wisatawan yang menganggap bahwa kondisi keamanan di Ubud aman dan yang paling sedikit adalah wisatawan yang beranggapan bahwa kondisi keamanan di Ubud adalah cukup aman.

18. Karakteristik Wisatawan Asia Berdasarkan Kepuasan Selama Berkunjung ke Ubud

Tabel 18.1

\begin{tabular}{|c|c|c|c|c|}
\hline \multirow[b]{2}{*}{$\begin{array}{l}\text { No } \\
\cdot\end{array}$} & \multirow{2}{*}{$\begin{array}{c}\text { Tingkat } \\
\text { Kepuasa } \\
\mathbf{n}\end{array}$} & \multicolumn{2}{|c|}{$\begin{array}{c}\text { Jumlah } \\
\text { Wisatawan }\end{array}$} & \multirow{2}{*}{$\begin{array}{c}\text { Persentas } \\
\text { e (\%) }\end{array}$} \\
\hline & & $\begin{array}{c}\text { First } \\
\text { Time } \\
r\end{array}$ & $\begin{array}{c}\text { Repeate } \\
r\end{array}$ & \\
\hline 1. & $\begin{array}{l}\text { Sangat } \\
\text { Puas }\end{array}$ & 47 & 5 & 49.52 \\
\hline 2. & Puas & 45 & 4 & 46.67 \\
\hline 3. & $\begin{array}{l}\text { Cukup } \\
\text { Puas }\end{array}$ & 4 & - & 3.81 \\
\hline 4. & $\begin{array}{l}\text { Kurang } \\
\text { Puas }\end{array}$ & - & - & - \\
\hline 5. & $\begin{array}{l}\text { Sangat } \\
\text { Kurang } \\
\text { Puas }\end{array}$ & - & - & - \\
\hline \multicolumn{2}{|c|}{ Jumlah } & 96 & $\begin{array}{ll} & 9 \\
05 & \end{array}$ & 100 \\
\hline
\end{tabular}

Sumber: Data dari hasil penelitian, 2016

Berdasarkan Tabel 18.1 dapat dilihat bahwa karakteristik wisatawan Asia berdasarkan kepuasan selama berkunjung ke Ubud yang paling banyak adalah wisatawan yang sangat puas dan yang paling sedikit adalah wisatawan yang cukup puas selama melakukan perjalanan ke Ubud.

19. Karakteristik Wisatawan Asia

Berdasarkan Keinginan Untuk Melakukan Kunjungan Ulang

Karakteristik wisatawan Asia berdasarkan keinginan untuk melakukan kunjungan ulang yang paling banyak adalah wisatawan yang ingin melakukan kunjungan ulang ke Ubud yaitu sebanyak 100 orang wisatawan atau sejumlah $95.24 \%$ dan sebanyak 5 (lima) orang atau sejumlah $4.76 \%$ ragu-ragu untuk melakukan kunjungan ulang ke Ubud.

20. Motivasi Wisatawan Asia ke

Kelurahan Ubud

Tabel 20.1

\begin{tabular}{|c|c|c|c|c|}
\hline \multirow{2}{*}{ No. } & Motivasi & \multicolumn{2}{|c|}{$\begin{array}{c}\text { Jumlah } \\
\text { Wisatawan }\end{array}$} & \\
\cline { 3 - 4 } Wisatawan & $\begin{array}{c}\text { First } \\
\text { Time } \\
\text { Time }\end{array}$ & $\begin{array}{c}\text { Repe } \\
\text { ater }\end{array}$ & \\
\hline 1. & Bersenang- & 73 & 4 & 73.33 \\
\hline
\end{tabular}

\begin{tabular}{|c|l|c|c|c|}
\hline & $\begin{array}{l}\text { senang/Tam } \\
\text { asya }\end{array}$ & & & \\
\hline 2. & Rekreasi & 10 & 2 & 11.43 \\
\hline 3. & Kebudayaan & 9 & 3 & 11.43 \\
\hline 4. & Konvensi & - & - & - \\
\hline 5. & Spiritual & 3 & - & 2.86 \\
\hline 6. & Kesehatan & - & - & - \\
\hline 7. & $\begin{array}{l}\text { Interpersona } \\
1\end{array}$ & - & - & - \\
\hline 8. & Olahraga & - & - & - \\
\hline 9. & Sosial & 1 & - & 0.95 \\
\hline 10. & Bisnis & - & - & - \\
\hline \multicolumn{2}{|l|}{ Jumlah } & $\mathbf{9 6}$ & $\mathbf{9}$ & \multirow{2}{|c|}{$\mathbf{1 0 0}$} \\
\cline { 2 - 3 } & & \multicolumn{105}{c}{} \\
\hline
\end{tabular}

Sumber: Data hasil penelitian, 2016

Berdasarkan Tabel 20.1 dapat dilihat bahwa motivasi wisatawan Asia yang datang berkunjung ke Ubud yang paling banyak adalah wisatawan yang datang dengan motif bersenang-senang atau tamasya yaitu sebanyak dan yang paling sedikit adalah wisatawan dengan motif sosial.

\section{Aktivitas Wisatawan Asia di Kelurahan Ubud}

Tabel 21.1

\begin{tabular}{|c|c|c|c|c|}
\hline \multirow[b]{2}{*}{$\begin{array}{l}\mathbf{N} \\
\text { o. }\end{array}$} & \multirow{2}{*}{$\begin{array}{c}\text { Aktivitas } \\
\text { Wisatawan }\end{array}$} & \multicolumn{2}{|c|}{$\begin{array}{c}\text { Jumlah } \\
\text { Wisatawan }\end{array}$} & \multirow{2}{*}{$\begin{array}{c}\text { Persenta } \\
\text { se }(\%)\end{array}$} \\
\hline & & $\begin{array}{c}\text { First } \\
\text { Tim } \\
\text { er }\end{array}$ & $\begin{array}{l}\text { Repeat } \\
\text { er }\end{array}$ & \\
\hline 1. & $\begin{array}{l}\text { Mengunjun } \\
\text { gi Monkey } \\
\text { Forest }\end{array}$ & 16 & 3 & 16.19 \\
\hline 2. & $\begin{array}{l}\text { Mengunjun } \\
\text { gi Museum }\end{array}$ & 8 & - & 9.52 \\
\hline 3. & $\begin{array}{l}\text { Mengunjun } \\
\text { gi Pasar } \\
\text { Ubud }\end{array}$ & 39 & 3 & 39.04 \\
\hline 4. & $\begin{array}{l}\text { Mengunjun } \\
\text { gi } \\
\text { Terasering } \\
\text { Tegallalang }\end{array}$ & 5 & 1 & 7.62 \\
\hline 5. & $\begin{array}{l}\text { Melakukan } \\
\text { Yoga/Medit } \\
\text { asi }\end{array}$ & - & - & - \\
\hline 6. & Trekking & 2 & - & 1.91 \\
\hline 7. & Bersepeda & 2 & - & 1.91 \\
\hline 8. & $\begin{array}{l}\text { Wisata } \\
\text { Kuliner }\end{array}$ & 2 & 2 & 2.86 \\
\hline 9. & Shopping & 7 & - & 6.67 \\
\hline 10 & $\begin{array}{l}\text { Belajar } \\
\text { Kesenian }\end{array}$ & 10 & - & 9.52 \\
\hline 11 & Bulan & 1 & - & 0.95 \\
\hline
\end{tabular}




\begin{tabular}{|c|c|c|c|c|}
\hline . & $\begin{array}{l}\text { Madu } \\
\text { (Lainnya) }\end{array}$ & & & \\
\hline $\begin{array}{c}12 \\
.\end{array}$ & $\begin{array}{l}\text { Fotografi } \\
\text { (Lainnya) }\end{array}$ & 2 & - & 1.91 \\
\hline 13 & $\begin{array}{l}\text { Spa } \\
\text { (Lainnya) }\end{array}$ & 1 & - & 0.95 \\
\hline $\begin{array}{c}14 \\
.\end{array}$ & $\begin{array}{l}\text { Mempelajar } \\
\text { i sejarah } \\
\text { Ubud } \\
\text { (Lainnya) }\end{array}$ & 1 & - & 0.95 \\
\hline \multirow{2}{*}{\multicolumn{2}{|c|}{ Jumlah }} & 96 & 9 & \multirow{2}{*}{100} \\
\hline & & \multicolumn{2}{|c|}{105} & \\
\hline
\end{tabular}

Sumber: Data hasil penelitian, 2016

Berdasarkan Tabel 21.1 dapat dilihat bahwa aktivitas yang paling banyak dilakukan oleh wisatawan Asia yang datang berkunjung ke Ubud adalah wisatawan yang ingin mengunjungi Pasar Ubud yaitu sejumlah 42 orang atau sejumlah 39.04\%.

\section{IV.}

\section{Pembahasan}

Karakteristik Wisatawan Asia yang paling banyak mengunjungi Ubud adalah wisatawan yang berusia 26-36 tahun yang berjenis kelamin laki-laki. Wisatawan yang paling banyak adalah wisatawan yang berasal dari China yang pekerjaannya adalah pelajar dan tingkat pendidikannya sarjana. Wisatawan Asia paling banyak mendapatkan informasi mengenai Ubud melalui travel agent yang berkunjung bersama group karena wisatawan yang paling banyak adalah wisatawan yang baru pertama kali datang berkunjung ke Ubud. kebanyakan dari wisatawan menggunakan mobil atau bus untuk mengunjungi Ubud. seluruh wisatawan menggunakan jalur transportasi udara ketika datang ke Bali dan selama di Bali menggunakan kendaraan sewaan. Wisatawan Asia paling banyak menetap di Ubud selama 1 (satu) hari dan tidak menggunakan tour serta daya tarik yang banyak dikunjungi adalah kebudayaan. Ratarata pengeluaran wisatawan Asia ketika berada di Ubud adalah antara Rp. 201.000-300.000. Menurut para wisatawan Asia, lingkungan di Ubud sangat bersih, kondisi lingkungannya aman sehingga mereka sangat puas ketika berkunjung ke Ubud dan akan melakukan kunjungan ulang.

\section{Simpulan dan Saran \\ 5.1 Simpulan}

Karakteristik, motivasi dan aktivitas wisatawan Asia yang datang berkunjung ke
Ubud berbeda-beda. Karakteristik dan motivasi mempengaruhi aktivitas yang akan dilakukan para wisatawan selama mereka berkunjung ke Ubud. Motivasi Wisatawan Asia ketika berkunjung ke Ubud yang paling banyak adalah wisatawan yang datang dengan motif bersenang-senang atau tamasya dan aktivitas yang paling banyak dilakukan adalah mengunjungi Pasar Ubud.

\subsection{Saran}

Para pelaku pariwisata di Bali, khususnya di Ubud harus lebih gencar dalam mempromosikan wisata yang ada di Ubud, mempertahankan keadaan kondisi Ubud yang natural dan tradisional, menjaga kebudayaan Ubud serta melestarikan dan menjaga sumber daya baik alam maupun buatan yang ada di Ubud.

\section{Daftar Pustaka}

Marpaung, Happy. 2002. Pengantar Pariwisata. Bandung: Alfabeta

Mathisen; Geoffrey. 1982. Anthropology.

McIntosh, R. W. 1972. Tourism, Principles, Practices, Philosophies. Ohio: Inc Press

Moeloeng, Lexy J. 2001. Metode Penelitian Kualitatif. Bandung: Remaja Rosdakarya

Pendit, Nyoman S. 1994. Ilmu Pariwisata Sebuah Pengantar. Jakarta: PT. Pradya Paramitha

Pitana, I Gede; Gayatri, Putu. 2005. Sosiologi Pariwisata. Yogyakarta: Andi Offset

Poon, A. 1993. Tourism, Technology and Competitive Strategies. Oxford: CAB International

Seaton, A. V; Bennet. 1996. Marketing Tourism Product. UK: Cengage Leaming

Sihite, Richard. 2000. Tourism Industry. Surabaya: SIC

Supranto, J MA. Statistik Teori dan Aplikasi. Jakarta: Erlangga

Suwantoro, Gamal. 1997. Dasar-dasar Pariwisata. Yogyakarta: Andi Offset

Undang-Undang Tentang Kepariwisataan No. 10 Tahun 2009

Wardiyanta. 2010. Metode Penelitian Pariwisata. Yogyakarta: Andi Offset 